\title{
Transplanted Mouse Embryonic Stem-Cell-Derived Motoneurons Form Functional Motor Units and Reduce Muscle Atrophy
}

\author{
Damien C. Yohn, ${ }^{1}$ Gareth B. Miles, ${ }^{1}$ Victor F. Rafuse, ${ }^{1 \star}$ and Robert M. Brownstone ${ }^{1,2 *}$ \\ Departments of ${ }^{1}$ Anatomy and Neurobiology and ${ }^{2}$ Surgery (Neurosurgery), Dalhousie University, Halifax, Nova Scotia, Canada B3H 1 X5
}

\begin{abstract}
Prolonged muscle denervation resulting from motor neuron (MN) damage leads to atrophy and degeneration of neuromuscular junctions (NMJs), which can impart irreversible damage. In this study, we ask whether transplanted embryonic stem (ES) cells differentiated into MNs can form functional synapses with host muscle, and if so what effects do they have on the muscle. After transplantation into transected tibial nerves of adult mice, ES-cell-derived MNs formed functional synapses with denervated host muscle, which resulted in the ability to produce average tetanic forces of $44 \%$ of nonlesioned controls. ES-cell-derived motor units (MUs) had mean force values and ranges similar to control muscles. The number of type I fibers and fatigue resistance of the MUs were increased, and denervationassociated muscle atrophy was significantly reduced. These results demonstrate the capacity for ES-cell-derived MNs not only to incorporate into the adult host tissue, but also to exert changes in the target tissue. By providing the signals normally active during embryonic development and placing the cells in an environment with their target tissue, ES cells differentiate into MNs that give rise to functional MU output which resembles the MU output of endogenous MNs. This suggests that these signals combined with those present in the graft environment, lead to the activation of a program intended to produce a normal range of $\mathrm{MU}$ forces.
\end{abstract}

Key words: amyotrophic lateral sclerosis; motor unit; muscle fiber; neuromuscular junction; peripheral nerve; transplantation; $\mathrm{Hb} 9$

\section{Introduction}

Degenerative neurological disorders are devastating because of the loss of functional neurons and the inability of the CNS to replace these neurons to effect repair. Neuronal replacement strategies have been studied in animal models and human clinical studies of neurodegenerative disorders, in particular Parkinson's disease (Björklund et al., 2003). These studies primarily used fetal cells for transplantation, and behavioral rather than physiological analyses to evaluate repair. Recently, attention has turned to embryonic stem (ES) cells as these can be expanded almost limitlessly in vitro (Lindvall and Kokaia, 2006), and developmental cues can be used to differentiate them into specific neuronal phenotypes (Wichterle et al., 2002; Miles et al., 2004).

Amyotrophic lateral sclerosis (ALS) is a debilitating motoneuron $(\mathrm{MN})$ disease characterized by muscle denervation and atro-

\footnotetext{
Received 0ct. 2, 2008; accepted 0ct. 4, 2008.

This work was supported by Project A.L.S. (R.M.B.) and the Natural Sciences and Engineering Research Council of Canada (V.F.R.). The HhAg1.4 was a generous gift from Curis. G.B.M. was supported by a New Zealand Foundation for Research Science and Technology postdoctoral fellowship (DALH0201). We thank Cindee Leopold, who cultured the ES cells.

*V.F.R. and R.M.B. contributed equally to this work.

Correspondence should be addressed to either of the following: Robert M. Brownstone, Departments of Surgery and Anatomy and Neurobiology, Faculty of Medicine, Sir Charles Tupper Medical Building, 5850 College Street, Halifax, Nova Scotia, Canada B3H 1X5, E-mail: rob.brownstone@dal.ca; or Victor F. Rafuse, Department of Anatomy and Neurobiology, Faculty of Medicine, Sir Charles Tupper Medical Building, 5850 College Street, Halifax, Nova Scotia, Canada B3H 1X5, E-mail: victor.rafuse@dal.ca.

G. B. Miles's present address: School of Biology, University of St Andrews, St Andrews, Fife KY16 9TS, UK. D0I:10.1523/JNEUROSCI.1761-08.2008

Copyright $\odot 2008$ Society for Neuroscience $\quad$ 0270-6474/08/2812409-10\$15.00/0
}

phy, and MN death ultimately leading to respiratory paralysis (Boillée et al., 2006). The replacement of MNs lost to disease is one strategy aimed at restoring connectivity of the CNS to muscle via neuromuscular junctions (NMJs), attenuating muscle atrophy, and reestablishing movement. The use of ES cells for MN replacement is dependent on successfully differentiating ES cells into functional MNs. The development of MNs can be recapitulated in vitro by applying retinoic acid (RA) and a sonic hedgehog (Shh) agonist to ES cells (Wichterle et al., 2002). We have previously shown that MNs derived using this protocol have physiological properties similar to endogenous MNs and can functionally innervate cocultured muscle fibers (Miles et al., 2004), making these cells promising for transplantation studies. We next showed that these cells preferentially differentiate into MNs of a specific phenotype (medial motor column or MMC), and that after transplantation into the developing chick spinal cord, they projected to muscles normally innervated by MMC MNs (axial muscle, (Soundararajan et al., 2006)). Implantation of these neurons into the adult spinal cord has proven challenging, but some success was recently reported (Deshpande et al., 2006). However, the degree to which implanted ES-cell-derived neurons innervate muscle, the force the reinnervated muscle can produce, the effects on muscle fiber type, and any resultant protection from muscle atrophy have not been assessed.

In this study, we assessed the capacity of ES-cell-derived MNs to functionally innervate muscle by using a model whereby the cells are implanted into the peripheral nervous system (Thomas et al., 2000; MacDonald et al., 2003; Li et al., 2005), thus avoiding 
the growth inhibiting environment of the CNS. Further, this strategy eliminates competition between implanted ES-cellderived MNs and endogenous MNs, thus ensuring the parameters measured after implantation were attributable to the transplants themselves. We found that transplantation of ES-cellderived $\mathrm{MNs}$ into a peripheral nerve resulted in functional innervation of muscle. Further, we present evidence of resulting muscle fiber type conversion of host muscle fibers and attenuated muscle atrophy. Such functional reinnervation represents a critical step en route to the development of neuronal replacement strategies for $\mathrm{MN}$ diseases and injuries.

\section{Materials and Methods}

Cell preparation. The HBG3 transgenic mouse ES cell line links the HB9 promoter, a homeobox gene expressed in MNs (Arber et al., 1999; Thaler et al., 1999), to drive eGFP expression to visualize differentiated MNs. ES-cell-derived MNs were cultured and differentiated using RA and a Shh agonist as previously described (Wichterle et al., 2002; Miles et al., 2004), with the exception that Hh-Ag1.4 (50 nM, Curis) was used in lieu of $\mathrm{Hh}-\mathrm{Ag} 1.3$. At $5 \mathrm{~d}$ of differentiation, the cells were dissociated using the Papain dissociation system (Worthington Biochemical) and maintained in DFK10 medium [as prepared by Miles et al. (2004)] supplemented with $0.5 \mathrm{mg} / \mathrm{ml}$ DNase (Sigma-Aldrich). For implantation, $\sim 1.0 \times 10^{6}$ differentiated ES cells were added to $10 \mu \mathrm{l}$ of DFK10-DNase medium, 20 $\mu \mathrm{g} / \mathrm{ml}$ CNTF (Upstate Biotechnology), and $10 \mu \mathrm{g} / \mathrm{ml}$ GDNF (Millipore Bioscience Research Reagents).

Surgery. All procedures were in accordance with protocols approved by the Dalhousie University Animal Care Committee, and conformed to the standards of the Canadian Council of Animal Care. We have modified our previously published technique [MacDonald et al. (2003), based on Erb et al. (1993)] and now implant the ES-cell-derived MNs into the tibial nerve just proximal to the nerve branch of the medial gastrocnemius (MG).

Using sterile technique under isoflurane anesthesia, C57BL/6 male mice at 5-6 weeks of age (Charles River Laboratories) had their sciatic nerve transected and the distal portion sutured into the nearby gluteus maximus muscle to prevent endogenous reinnervation through the graft site (MacDonald et al., 2003). All nerve branches from the tibial nerve were transected (Fig. 1, dotted lines), with the exception of the MG nerve, to channel axonal outgrowth (Fig. 1, arrows). Approximately 10,000 dissociated ES-cell-derived MNs contained within $1 \mu \mathrm{l}$ of medium were injected into the tibial nerve using a fine borosilicate glass capillary tube (World Precision Instruments) pulled on a PP830 pipette puller (Narishige) to an inner diameter of between 40 and $50 \mu \mathrm{m}$. The injection site was $15 \mathrm{~mm}$ from the MG nerve-muscle entry point. Ligatures were placed along the tibial nerve to confine the injectate as illustrated in Figure 1.

The results presented are compared with control animals (uninjured, not implanted) and surgical control animals (nerve transected and reflected to prevent reinnervation, only medium injected; i.e., denervated).

Electrophysiological analysis. After 60-90 d of implantation, animals were killed, and the MG muscle, MG nerve, and tibial nerve containing the graft were quickly removed and transferred into a recording chamber that was continuously perfused with room temperature oxygenated mouse Tyrode's solution ( $125 \mathrm{~mm} \mathrm{NaCl}, 24 \mathrm{~mm} \mathrm{NaHCO}_{3}, 5.4 \mathrm{~mm} \mathrm{KCl}, 1$ $\mathrm{mm} \mathrm{MgCl} 2,1.8 \mathrm{~mm} \mathrm{CaCl}_{2}$, and $5 \%$ dextrose) at a flow rate of $4-5 \mathrm{ml} / \mathrm{min}$. The knee joint was secured to the bottom of the recording chamber and the distal tendon of the MG muscle was secured to a force displacement transducer (Grass FT03) using a suture. EMG recordings were obtained using a suction electrode on the surface of the muscle while a second suction electrode was used to stimulate the tibial nerve. The nerve-muscle preparations were sustainable for $30 \mathrm{~h}$ without noticeable physiological degradation such as loss of force, changes in contraction times, or fatigability. Force and EMG signals were amplified with a differential amplifier (EX4-400, Dagan), captured using Axoscope 9.2 software (Molecular Devices).

Twitch and tetanic forces were recorded in response to stimuli of the tibial nerve using an S88 square pulse stimulator (Grass Instruments).

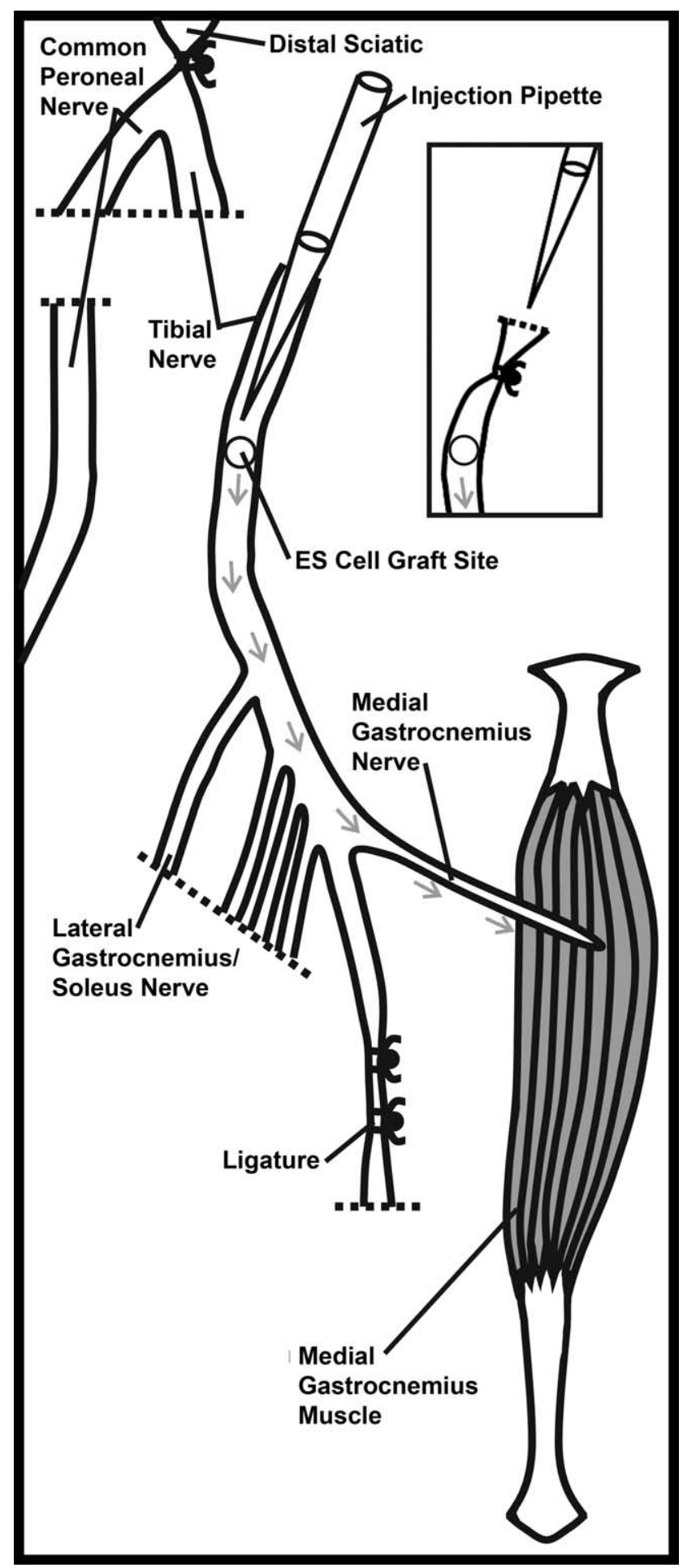

Figure 1. Injection of ES-cell-derived MNs into the adult mouse tibial nerve. Dissociated ES-cellderived MNs were injected through a fine glass capillary into the tibial nerve. Direction of neurite outgrowth (arrows) was restricted to the medial gastrocnemius nerve by transecting all other branches from the tibial nerve (dotted lines). The injection pipette was withdrawn as a ligature proximal to the injection site was simultaneously tightened around the tibial nerve to prevent implanted cells from escaping (inset). Ligatures were placed distal to the injection site to further secure the implanted cells and to prevent endogenous nerves from infiltrating the implanted nerve.

Three responses were averaged on line in response to either 1 or 16 stimulus pulses ( $20 \mu$ s pulse duration) at $50 \mathrm{~Hz}$ for $0.5 \mathrm{~s}$. Maximal force was determined by increasing the intensity of the stimulus until a stable force was reached. Rise times were calculated as the time from initial 
force onset to maximum peak force using twitch stimulation. The susceptibility of the muscle to fatigue was quantified with a stimulation protocol of 13 pulses at $40 \mathrm{~Hz}$ every second for $2 \mathrm{~min}$ (Burke et al., 1973). Fatigue indices quantified force degradation over time and were calculated as the ratio between the force at each of 1 and $2 \mathrm{~min}$, divided by the initial force at $t=0$.

Motor unit size was estimated by increasing the stimulus applied to the nerve stump to recruit all-or-none incremental and unique steps in force and EMG (McComas et al., 1971). To record discrete MUs in the control animals, the number of MUs was reduced by cutting a portion of the sciatic nerve until only $30 \%$ of the initial force remained. In addition, a maximum of 7 force increments were measured per animal. This restriction minimized the probability of assessing alternations in unit recruitment which would otherwise overestimate the number of MUs innervating the MG muscle (Stein and Yang, 1990). Individual MU twitch forces were subsequently obtained by digital subtraction. The number of MG MUs was estimated by dividing whole-muscle twitch force by the average control MU force.

Mean \pm SE are reported. Data were pooled within each group (Fu and Gordon, 1995a). Differences between mean values were analyzed using a one-tailed Student's $t$ test, with $p<0.05$ taken as significant.

Tissue analysis. Wet weight measurements of the MG muscle were performed after electrophysiological analysis. Muscles were flash frozen as in Schultz et al. (1986). Coronal cryostat sections (30 $\mu \mathrm{m})$ were obtained and the largest midbelly section of the muscle was evaluated for cross-sectional area. Muscle fiber type was determined using the mouse anti-S58 (slow myosin) antibody (1:5; Developmental Studies Hybridoma Bank) and either mouse anti-A4.74 (1:10; Developmental Studies Hybridoma Bank) or mouse anti-skeletal myosin (1:500; Sigma Immuno Chemicals) for fast myosin. Tissue fixation in $-20^{\circ} \mathrm{C}$ acetone, and subsequently $3.7 \%$ formaldehyde, followed S58 antibody application. Secondary antibodies conjugated to FITC (1:250, MP Biomedicals or Cy3 (1:250; Millipore Bioscience Research Reagents) were used. Quantification of fiber size and numbers of immunohistochemically stained tissue was performed using Zeiss AxioVision 4.4 software. Determination of reinnervated muscle fiber number through glycogen depletion of the muscle was unsuccessful as has been reported by other groups using in vitro preparations (Zardini and Parry, 1998).

Flash-frozen cryostat sectioned $(10 \mu \mathrm{m})$ nerve was fixed in $3.7 \%$ formaldehyde. Primary antibodies consisted of mouse anti-SMI-99 (1:1000; Sternberger Monoclonal Antibodies) for myelin basic protein and rabbit anti-eGFP (1:1000; Millipore Bioscience Research Reagents). Secondary antibodies were as above. Toluidine blue staining of grafted nerve was prepared as described by Gould et al. (2006).

Whole-mount immunohistochemistry was performed in tissue extracted from animals that were transcardially perfused with $4 \%$ paraformaldehyde [adapted from the study by Lubischer and Thompson (1999) ]. After overnight postfix, the tissue was treated with $-20^{\circ} \mathrm{C}$ methanol then immunostained for eGFP. Rhodamine-conjugated $\alpha$-bungarotoxin (1:100; Invitrogen) was applied to visualize AChRs.

\section{Results \\ ES-cell-derived MNs survive and form neuromuscular junctions after implantation}

To assess whether ES-cell-derived MNs have the capacity to survive and functionally innervate limb muscle after transplantation, we modified an established model used for neuronal transplantation into the peripheral nervous system (Erb et al., 1993; Thomas et al., 2000; MacDonald et al., 2003). After sectioning the sciatic nerve proximally, dissociated, differentiated ES cells were transplanted into the tibial nerve $\sim 15 \mathrm{~mm}$ proximal to the $\mathrm{MG}$ nerve-muscle entry point (Fig. 1). Anatomical analysis of ES-cellderived MNs was performed in whole-mount tibial nerve-MG muscle preparations where eGFP expression was used to visualize the surviving cell bodies and neurites (Fig. 2). The left portion of Figure 2 depicts a schematic of the injection site in the tibial nerve (Box A) and the representative extension of neurites in the MG nerve stump (Box B), nerve-muscle entry point (Box D), and the NMJs (Box E).

Cell survival was observed up to 11 months in vivo (the longest time point investigated). Survival of transplanted ES-cell-derived MNs was dependent on the inclusion of CNTF and GDNF in the implant medium as grafted cells did not survive beyond $7 \mathrm{~d}$ when the growth factors were not included ( $n=16$, data not shown). CNTF $(20 \mu \mathrm{g} / \mathrm{ml})$ and GDNF $(10 \mu \mathrm{g} / \mathrm{ml})$ used for all of our subsequent in vivo experiments was $1000 \times$ that used in our previous coculture experiments (Miles et al., 2004). This concentration ratio was based on the GDNF concentrations used to support dopaminergic neuron survival in vivo versus in vitro (McLeod et al., 2006). Immunosuppression was not necessary for graft survival as the ES cells were derived from the same mouse strain (i.e., $\mathrm{C} 57 \mathrm{BL} / 6)$ as the transplant recipients.

Cell bodies, with projecting neurites, were localized within the tibial nerve at the site of injection from 1 d onwards $(n=24)$ (Fig. $2 A)$. By $14 \mathrm{~d}$ after transplantation, many ES-cell-derived MNs had extended neurites into the MG nerve $(n=3)$. Similar projections toward the MG muscle were seen up to $90 \mathrm{~d}$ after transplantation (60 d shown in Fig. $2 B$ ). Histological analysis $(n=2)$, using either an antibody against myelin basic protein (Fig. $2 C^{\prime}-$ $\left.C^{\prime \prime \prime}\right)$ or toluidine blue staining (data not shown), showed that the $\mathrm{eGFP}^{+}$neurites were myelinated or undergoing myelination. In the nerve to the MG muscle, there were a total of 23 and 27 myelinated axons, respectively, compared with a total of 54 axons counted in this nerve in an Hb9:eGFP transgenic mouse. As the nerve entered the muscle, different $\mathrm{GFP}^{+}$neurites followed distinct nerve branches (Fig. 2D). Next, rhodamine-conjugated $\alpha$-bungarotoxin was used to label postsynaptic acetylcholine receptors at the motor endplates to anatomically assess synapse formation $(n=2)$. Figure $2 E$ shows an example of $\mathrm{eGFP}^{+}$axons (Fig. $\left.2 E^{\prime}, E^{\prime \prime \prime}\right)$ in apposition to two motor endplates (Fig. $2 E^{\prime \prime}, E^{\prime \prime \prime}$ ) $60 \mathrm{~d}$ after transplantation. These data demonstrate that ES-cellderived MNs survive, extend axons, and contact denervated motor endplates in the months after implantation.

\section{Electrical stimulation of implanted cells results in host muscle contraction}

To determine whether the contacted endplates formed functional NMJs, we proceeded to stimulate the peripheral nerves in isolated nerve-muscle preparations from animals transplanted with EScell-derived MNs 60-90 d previously (see supplemental Video, available at www.jneurosci.org as supplemental material). The average time from stimulus to EMG response was $3.2 \mathrm{~ms}$ in the implanted animals $(n=6)$ compared with $2.2 \mathrm{~ms}$ in the control animals $(n=4)$. The distance from the stimulating electrode to the neuromuscular junction was estimated to be $\sim 15 \mathrm{~mm}$. Assuming $1 \mathrm{~ms}$ delay from the action potential arriving at the terminal to the EMG response, this would equate to a mean conduction velocity of $6.7 \mathrm{~m} / \mathrm{s}$ in the implanted group compared with $12.1 \mathrm{~m} / \mathrm{s}$ in the control animals. However, given that these experiments were done at $\sim 20^{\circ} \mathrm{C}$, and that synaptic transmission and the EMG response would have $\mathrm{Q}_{10}$ of 3 , and conduction velocity $\mathrm{Q}_{10}$ of 1.7 (Huxley, 1959), these values would be considerably higher at $35^{\circ} \mathrm{C}$ and likely similar to the range previously demonstrated for mouse motor axons (Lewis et al., 1982). Figure $3 A$ shows typical twitch force recordings from a reinnervated $M G$ muscle and a MG muscle from an age matched control mouse. The twitch response from the reinnervated MG muscle indicates that the ES-cell-derived MNs formed functional synapses with denervated muscle fibers. Further, implanted nerve-muscle preparations elicited an average twitch force of $14.3 \pm 4.4 \mathrm{mN}$ 

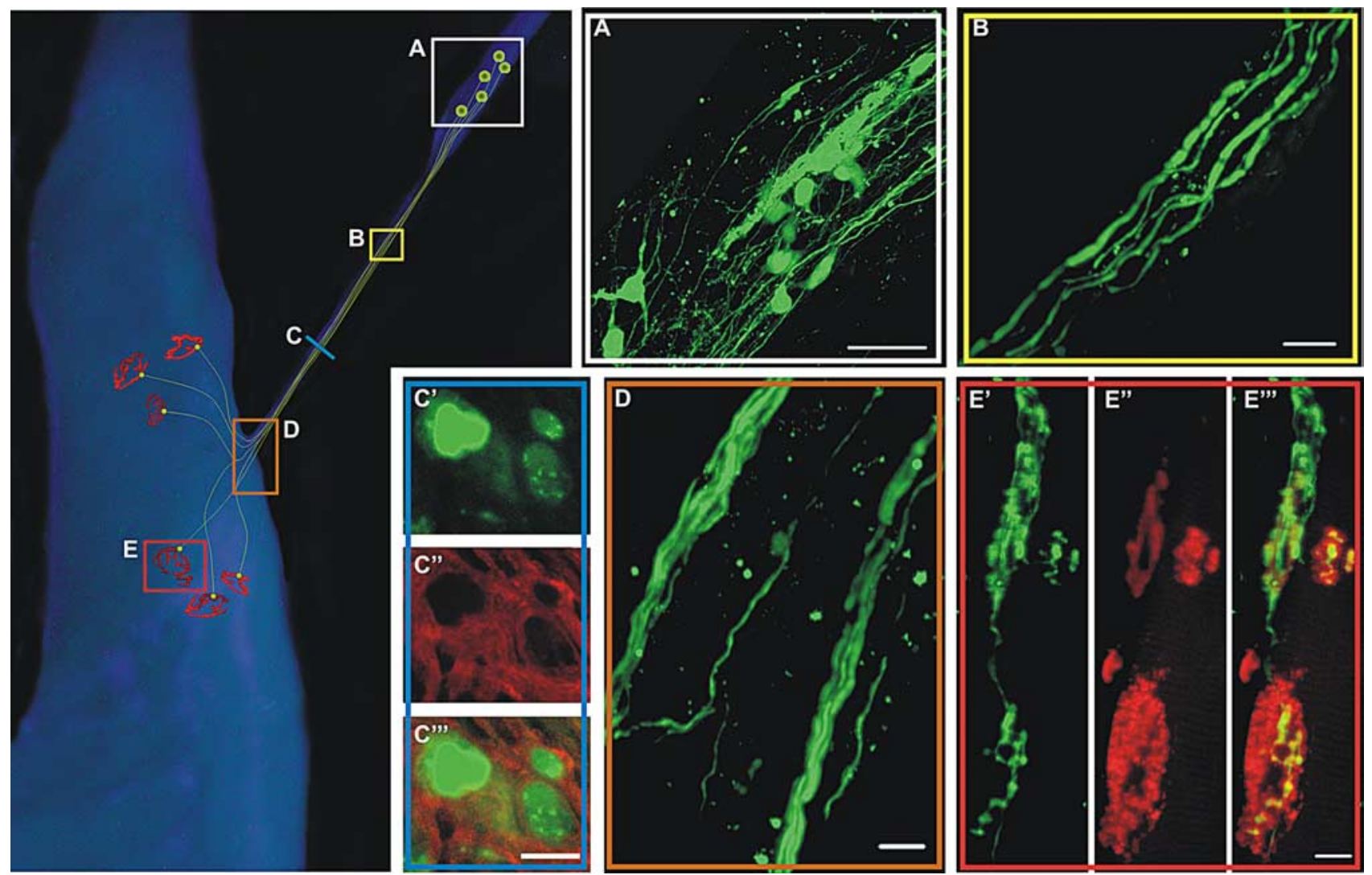

Figure 2. Implanted ES-cell-derived MNs form anatomical connections with host muscle fibers. Schematic at left side of figure depicts representative survival of tibial implanted ES-cell-derived MNs with associated axon outgrowth and connectivity to host muscle fibers. Colored squares correspond to confocal imaged regions of transplanted animals. Three months posttransplantation multiple eGFP ${ }^{+}$cell bodies from ES-cell-derived MNs were observed, using whole-mount confocal microscopy, in the tibial nerve $(\boldsymbol{A})$ and extended axons into the medial gastrocnemius nerve $(\boldsymbol{B})$. eGFP ${ }^{+}$axons in cross section $\left(\boldsymbol{C}^{\prime}\right)$ were surrounded by myelin basic protein $\left(\right.$ red) $\left(\boldsymbol{C}^{\prime \prime}\right)$, suggesting myelination of implant-derived axons by Schwann cells ( $\left.\boldsymbol{C}^{\prime \prime \prime}\right)$. Distinct nerve branching was observed at the region where the nerve enters the muscle $(\boldsymbol{D})$. $\alpha$-Bungarotoxin-labeled acetylcholine receptors of the host muscle $\left(\boldsymbol{E}^{\prime \prime}\right)$ were colocalized with eGFP ${ }^{+}$axons $\left(\boldsymbol{E}^{\prime}\right)$, suggesting that implantderived cells were forming connections with host muscle fibers $\left(\boldsymbol{E}^{\prime \prime \prime}\right)$. Scale bars: $\boldsymbol{A}, 100 \mu \mathrm{m} ; \boldsymbol{B}, \boldsymbol{D}, 20 \mu \mathrm{m} ; \boldsymbol{C}^{\prime \prime \prime}$ (for $\left.\boldsymbol{C}^{\prime}-\boldsymbol{C}^{\prime \prime \prime}\right), \boldsymbol{E}^{\prime \prime \prime}\left(\right.$ for $\left.\boldsymbol{E}^{\prime}-\boldsymbol{E}^{\prime \prime \prime}\right), 10 \mu \mathrm{m}$

$(n=6)$, approximately one-third that of the control twitch forces, which averaged $43.2 \pm 3.3 \mathrm{mN}(n=8, p<0.001)$ (Fig. $3 A)$. Tetanic forces in the implanted nerves averaged $39.1 \pm 8.8 \mathrm{mN}(n=6)$, approximately one-half that of the control tetanic forces of $88.7 \pm 2.9 \mathrm{mN}(n=7, p<$ 0.001) (Fig. 3B). Because the mouse MG muscle is predominantly composed of fast twitch muscle fibers (Brasseur et al., 1987) the peak force during an unfused tetanus eventually declines or "sags" with each successive stimulus (Burke et al., 1973). Interestingly, stimulating the reinnervated MG muscles (Fig. 3B, lower trace) at the same frequency (i.e., $50 \mathrm{~Hz}$ ) as the control animals (Fig. 3B, upper trace) produced a fused tetanus that remained relatively stable over the course of the stimulation. This change in "sag" property suggests that the contractile properties of the reinnervated muscle fibers differ from normal MG fibers (see below). In the rat, a twitchtetanic ratio at a tetanic stimulation of $50 \mathrm{~Hz}$ yields a value of $\sim 0.48$ (Mrówczyński et al., 2006) corresponding to our control twitch-tetanic ratio of $\sim 0.44 \pm 0.04(n=5)$, also with a $50 \mathrm{~Hz}$ tetanic stimulation. The twitch-tetanic forces of the implant

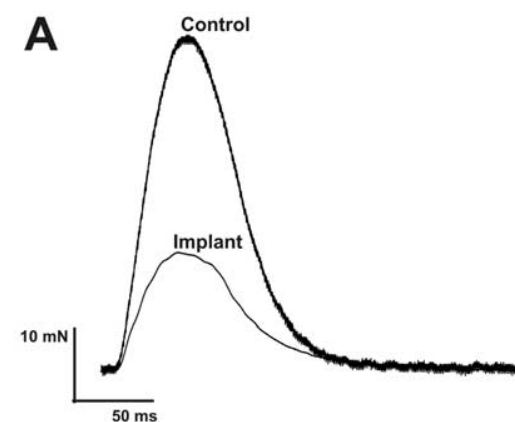

B
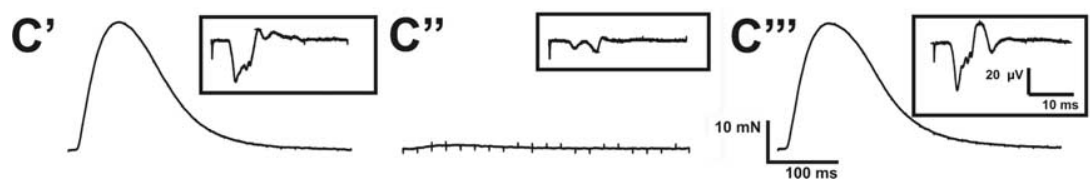

Figure 3. Functional reinnervation of host muscle fibers by implantation of ES-cell-derived MNs. Electrical stimulation of implanted tibial nerve resulted in contractile muscle force using twitch stimulation $(A, n=8$ control, $n=6$ implanted) and $50 \mathrm{~Hz}$ tetanic stimulation ( $\boldsymbol{B}, n=7$ control, $n=6$ implanted). Muscle contraction $\left(\boldsymbol{C}^{\prime}\right)$, via nerve stimulation, was mediated through the neuromuscular junction, because bath application of D-tubocurarine $(5 \mu \mathrm{M})$ effectively attenuated muscle force and EMG activity $\left(\mathbf{C}^{\prime \prime}\right)$, which was restored to baseline levels after a $3 \mathrm{~h}$ washout period $\left(\mathbf{C}^{\prime \prime}\right)$.

group $(0.51 \pm 0.12, n=6)$ were not significantly different from those of the control group indicating similarity between the physiological properties of the newly formed motor units (MUs) and those of control MUs. 


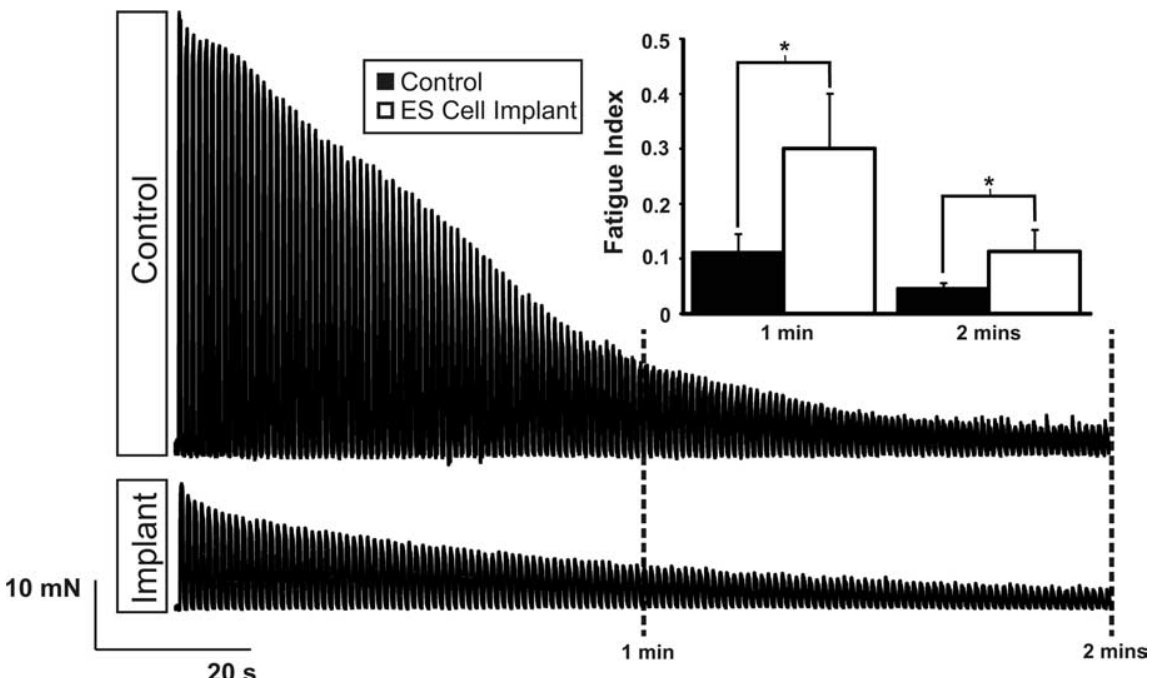

Figure 4. ES-cell-derived motor units are relatively fatigue resistant. Repetitive stimulation of isolated nerve-muscle preparations (13 pulses at $40 \mathrm{~Hz}$ delivered every second for $2 \mathrm{~min}$ ) in conjunction with force recordings was used to assess muscle fatigability. Fatigue index ratios were determined by comparing the force at 1 or 2 min with that of the initial force. Control animals demonstrated significantly greater levels of fatigue than did animals receiving ES-cell-derived MN implants (inset graph). The bar graph represents mean values \pm SEM of pooled data from six control animals and four implanted animals. ${ }^{*} p<0.05$.

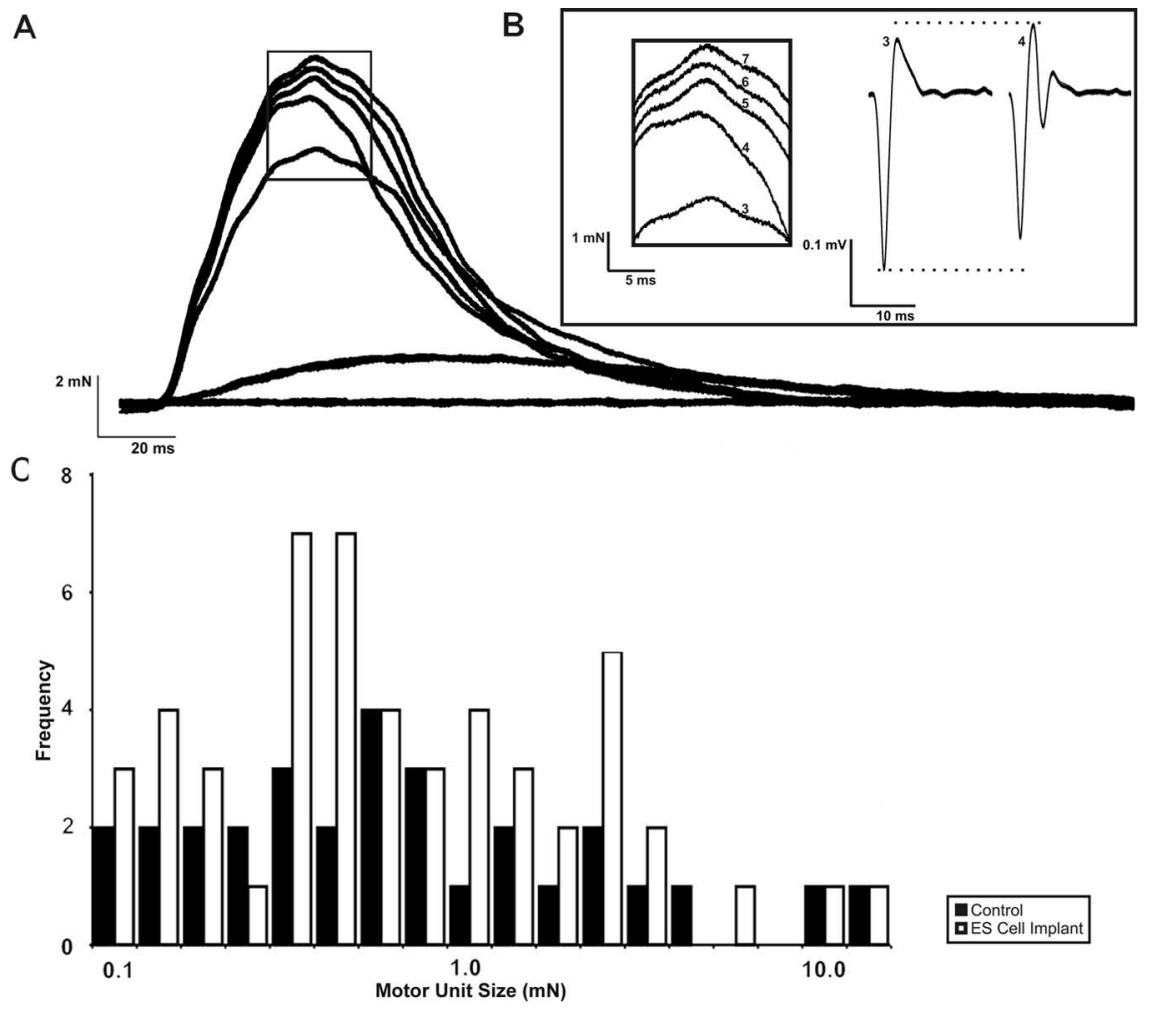

Figure 5. Motor unit analysis of reinnervated nerve-muscle preparations. Motor unit identification from incremental force steps in twitch muscle contraction elicited by stepwise increments in nerve stimulus amplitude to a maximum of seven units $(\boldsymbol{A})$. EMG recordings independently verified individual MUs, as demonstrated by unique EMG profiles for MUs 3 and 4 from inset (B). Force values from control and ES cell implant MUs had similar frequency distributions (C).

To confirm that the muscle contractions resulted from neurotransmission at the NMJs formed by the transplanted ES-cellderived $\mathrm{MNs}$, the competitive nicotinic antagonist D-tubocurarine $(5 \mu \mathrm{M})$ was bath applied to the recording solution. Figure $3 C$ shows that twitch force and EMG activity were blocked with D-tubocurarine (Fig. $3 C^{\prime \prime}$ ) and that this blockade was reversed after a 3 h washout period $(n=3)$ (Fig. $\left.3 C^{\prime \prime \prime}\right)$. Furthermore, surgical control animals which were implanted with medium alone (no ES-cell-derived MNs) did not demonstrate muscle contractions with nerve stimulation of up to $50 \mathrm{~V}(n=6$; data not shown), demonstrating that no endogenous axonal function either remained or was reestablished. These data demonstrate functional innervation of the endogenous MG muscle by implanted EScell-derived MNs (see also supplemental Video, available at www.jneurosci.org as supplemental material). The characteristics of the forces produced, however, were different from those of control animals, with lower forces and atypical contractile properties.

\section{Reinnervated MG muscles are more resistant to fatigue}

The mouse MG muscle contains a heterogeneous population of slow and fast muscle fibers with $\sim 50 \%$ of them being fatigable (Zhan et al., 1999). Consequently, during a fatigue test in which the nerve is repetitively stimulated, whole muscle force declines (Fig. 4). Interestingly, the reinnervated muscles $(n=4)$ had a relatively slower decline in force compared with the control group $(n=6)$ (Fig. 4). Fatigue indices quantified the reduction in force over time for both the control and implant groups at one and 2 min (Fig. 4, dotted lines). The fatigue indices of the implant group $(0.30 \pm 0.10)$ were significantly higher than for those of the control group $(0.11 \pm 0.03)$ at $1 \mathrm{~min}(p<0.001)$ (Fig. 4, graph). This trend of fatigue indices also persisted at $2 \mathrm{~min}$ where the implant group $0.11 \pm 0.04$ ) was significantly higher than the control group (0.05 \pm $0.01)(p<0.05)$ (Fig. 4, graph), indicating less fatigue in the implanted group. Together with the lack of "sag" in the implant group during $50 \mathrm{~Hz}$ stimulation (Fig. 3B), these results support the conclusion that the reinnervated muscle had an increased proportion of slow, fatigue-resistant MUs.

\section{ES-cell-derived MUs}

The number and size of MUs in normal and reinnervated MG muscles were quantified by systematically increasing the stimulus that was applied to the innervating nerve (Fig. 5A) (McComas et al., 1971) (see Materials and Methods for details). Figure $5 A$ shows the recruitment of seven MUs in a MG muscle that was reinnervated by ES-cell-derived MNs $76 \mathrm{~d}$ after transplantation. To ensure that each force step reflected a distinct MU, EMG recordings were also compared (McComas et al., 1971). For example, in Figure 5, the area within the rectangle (Fig. 5A) was enlarged to show that both the twitch forces and EMGs for MUs 
3 and 4 were unique and thus were classified as distinct MUs (Fig. 5B). Motor unit forces were then obtained by digitally subtracting the discrete increments in twitch force. Interestingly, the mean MU forces were similar in both the reinnervated $(1.2 \pm 0.3 \mathrm{mN}, n=8,51$ pooled MUs) and control muscles $(1.3 \pm 0.5 \mathrm{mN}, n=5,30$ pooled MUs) (Fig. 5C). In addition, EScell-derived MNs reestablished the normal range of MU forces (Fig. 5C).

The number of MUs in the control and reinnervated MG muscles was estimated by dividing whole-muscle twitch force by the average MU twitch force recorded from that muscle. On average, control muscles contained an estimated 32 MUs, whereas muscles reinnervated by ES-cellderived MNs contained an estimated 14 units. The number of MUs in control mouse MG muscles in the present study was slightly lower than the estimated $50 \pm$ 7 mouse MG units reported using anatomical techniques (Mohajeri et al., 1998) and seen using anatomical methods in this study (see above). This difference is probably attributable to the fact that our calculations under represent less forceful units because electrical stimulation recruits the largest MUs first (Jack, 1975). Regardless of the absolute numbers, these data indicate that the denervated MG muscle is reinnervated by one-third to one-half of its normal complement of MUs 60-90 d after transplantation. Furthermore, both the range and size of the reinnervated MUs were remarkably similar to those found in normal mouse MG muscles.

The average rise time of the twitch forces recorded from the control MG muscles was $40.2 \pm 1.6 \mathrm{~ms}$; this rise time is comparable to other fast twitch rodent muscles recorded at similar temperatures [i.e., $20^{\circ} \mathrm{C}$ (Stein et al., 1982)]. Interestingly, twitch force rise times in the implanted group $(44.7 \pm 1.5 \mathrm{~ms})$ were significantly slower than twitch rise times in the control group $(p<0.05)$. This higher average rise time suggests that the reinnervated muscles contained an increased proportion of slow MUs relative to the normally predominant fast MUs of the mouse MG (Brasseur et al., 1987; Zhan et al., 1999). However, MUs with both fast (Fig. $5 A$, MUs 3-7) and slow rise times (Fig. 5A, MUs 1,2) were present.

\section{There is an increase in the number of slow muscle fibers} after implantation

Immunohistochemistry was performed on control and reinnervated MG muscles to determine whether the ES-cell-derived MNs influenced the biochemical properties of the muscle fibers they innervated. Muscle cross sections through the midbelly of the MG were collected and stained with myosin heavy chain spe- cific antibodies. Slow muscle fibers were identified with anti-S58 (Miller et al., 1985) (Fig. 6A, $A^{\prime}, D, D^{\prime}, G, G^{\prime}$ ), whereas fast muscle fibers were identified with anti-A4.74 (data not shown) (Jergović et al., 2001) or mouse anti-skeletal myosin (Naumann and Pette, 1994) (Fig. $\left.6 B, B^{\prime}, E, E^{\prime}, H, H^{\prime}\right)$. The immunolabeling of $\mathrm{S} 58$ slow fibers in the control (Fig. $6 A^{\prime}$ ) and surgical control groups (Fig. 6G') was sparse as previously reported (Brasseur et al., 1987), whereas staining was prominent in the ES cell implant group (Fig. $6 D^{\prime}$ ). In addition, slow muscle fibers in the implanted animals were grouped, a further indicator of $\mathrm{MN}$ reinnervation and subsequent muscle fiber type conversion (Karpati and Engel, 1968; Thomas et al., 2000). The clustering of slow fibers in a single 

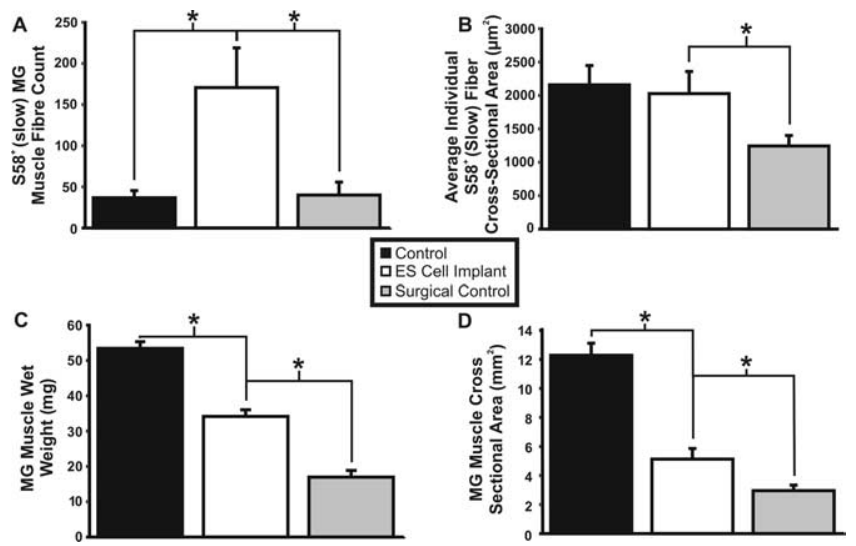

Figure 7. Analysis of muscle anatomy. The total number of $\mathrm{S}_{5} 8^{+}$(slow) muscle fibers is significantly greater in $\mathrm{ES}$ cell implantation medial gastrocnemius muscles than either control or surgical control ( $A, n=4$ control, $n=6$ implanted, $n=4$ surgical control). Cross-sectional areas of 15 individual $558^{+}$fibers per muscle were measured and averaged. Individual averages of the cross-sectional area of $\mathrm{S} 8^{+}$muscle fibers was significantly greater than $\mathrm{S}_{5} 8^{+}$ fibers in surgical control, but not significantly different from $\mathrm{S}^{+}{ }^{+}$fibers in control muscles ( $\boldsymbol{B}$, $n=4$ control, $n=5$ implanted, $n=5$ surgical control). ES-cell-derived MN implantation significantly attenuates muscle atrophy. ES cell implantation results in medial gastrocnemius muscle with a significantly greater weight and cross-sectional area than surgical control animals [ $\boldsymbol{C}(n=6$ control, $n=5$ implanted, $n=4$ surgical control), $\boldsymbol{D}$ ( $n=4$ control, $n=5$ implanted, $n=4$ surgical control), respectively]. However, implant group muscles were significantly lighter and smaller in cross section than control muscles ( $\boldsymbol{C}, \mathbf{D}$, respectively). Bar graphs represent mean values \pm SEM. ${ }^{*} p<0.05$.

region of the muscle may indicate that slow-type ES-cell-derived MNs (see Soundararajan et al., 2006) reinnervated the original slow region of the muscle and then expanded their territory (Fig. $6 D, F$ ) (Slack and Pockett, 1981; Bodine-Fowler et al., 1990; Nemeth et al., 1993; Rafuse and Gordon, 1996a,b) The innervation of these fibers by type S MNs would then convert them to type I muscle fibers (Foehring et al., 1987a,b), resulting in the demonstrated region of increased numbers of type I fibers. Fast fiber staining did not colocalize with S58 staining in control and ES implant groups (Fig. $6 C^{\prime}, F^{\prime}$, respectively) indicating that muscle fiber conversion was complete by $60 \mathrm{~d}$ after ES-cell-derived $\mathrm{MN}$ implantation. Interestingly, several slow muscle fibers in the denervated surgical control group coexpressed fast myosin heavy chains (Fig. $6 I^{\prime}$ ) suggesting that inactivity and/or denervation changed the biochemical composition of the noninnervated fibers (Gundersen et al., 1988).

We next proceeded to quantify the muscle fiber type conversion, and found a significant $(p<0.05)$ increase in the number of slow muscle fibers in the implant group $(171 \pm 48, n=6)$ (Fig. 6) when compared with both control $(37 \pm 9, n=4)$ and surgical control $(41 \pm 16, n=4)$ groups (Fig. $7 A)$. The average crosssectional area of individual slow muscle fibers of the implant group (2027 $\left.\pm 332 \mu \mathrm{m}^{2}, n=5\right)$ was similar to that of the control group (2159 $\left.\pm 290 \mu \mathrm{m}^{2}, n=4\right)$, and significantly greater $(p<$ $0.05)$ than that observed in the denervated, surgical control group $\left(1243 \pm 157 \mu \mathrm{m}^{2}, n=5\right)$ (Fig. $7 B$ ). Because the slow muscle fibers of the implant group had similar cross-sectional areas to controls, it can be inferred that these fibers were innervated as they did not undergo the atrophy observed in the surgical control group. The fast fibers remaining in the implant group muscle also had cross-sectional areas comparable to the control fast muscle fibers (data not shown) indicating that the remaining fast fibers were likely also innervated. Together, these results indicate that ES-cell-derived MNs have the capacity to change the contractile and biochemical properties of the normally fast contracting MG muscle and innervate both fast and slow muscle fibers. Further, because the conversion of muscle fiber phenotypes involves altered activity (Pette et al., 1972), these findings suggest that the transplanted ES-cell-derived MNs were functionally active (see supplemental Fig. 1, available at www.jneurosci.org as supplemental material, and Discussion).

\section{ES-cell-derived MNs attenuate muscle atrophy}

A qualitative comparison of the representative muscle crosssectional area revealed that the implanted group (Fig. 6E) was larger than the nonimplanted (surgical control) group (Fig. $6 \mathrm{H}$ ), yet not as large as the control group (Fig. 6B). To assess this further, we compared muscle wet weights (Fig. 7C) and crosssectional areas of the largest midbelly section of the MG muscles across groups (Fig. 7D). In comparison with the surgical control group, the muscle weight of the implant group was double ( $34 \pm$ $8 \mathrm{mg}, n=5$, compared with $17 \pm 3 \mathrm{mg}, n=4, p<0.05)$. As well, the implant group retained $>50 \%$ of the relative control weight $(53 \pm 4 \mathrm{mg}, n=6)$. Muscle cross-sectional area measurements paralleled the observations of muscle wet weight, with the implant group measuring $5.1 \pm 0.7 \mathrm{~mm}^{2}(n=5)$, compared with the surgical control of $3.0 \pm 0.4 \mathrm{~mm}^{2}(n=4, p<0.05)$, and the normal control area of $12.3 \pm 0.8 \mathrm{~mm}^{2}(n=4, p<0.0001)$. These results suggest that, by forming functional connections with host muscle, ES-cell-derived MNs limit denervation atrophy.

\section{Discussion}

The inability of the human CNS to repair itself after neuronal death has resulted in the need to establish methods to repair damaged circuits. ES cells have the proliferative capacity to provide an unlimited source of cells in vitro, and after differentiation into a specific cell type offer a potential substrate for cell replacement therapies. The generation of ES-cell-derived MNs from both mouse and human sources (Wichterle et al., 2002; Li et al., 2005) has led to the possibility that ES cells could be used for MN specific diseases such as ALS. ES-cell-derived MNs exhibit functional characteristics of endogenous MNs in terms of their ion channels, receptors, transmitter expression, and electrophysiological properties (Wichterle et al., 2002; Miles et al., 2004; Li et al., 2005), making them potential candidates for cell replacement strategies. We and others have demonstrated functional innervation in vitro between cocultures of ES-cell-derived MNs and mouse muscle fibers (Miles et al., 2004; Harper et al., 2004; Li et al., 2005). Currently there is little known about the in vivo capacity for ES-cell-derived MNs to form functional NMJs and how this capacity compares to endogenous MNs. In the present study, we demonstrate that after transplantation into the peripheral nervous system, ES-cell-derived MNs functionally innervate adult mouse muscle fibers, develop relatively normal MUs, and attenuate muscle atrophy.

Studies investigating either human or mouse ES-cell-derived MNs transplanted into rat spinal cords in which a subset of endogenous MNs were killed demonstrated axons that exited the spinal cord, entered host muscle, and reinnervated some NMJs (Gao et al., 2005, 2007; Deshpande et al., 2006). However, the presence of endogenous MNs, axons, and endogenously innervated NMJs in these studies precluded the assessment of newly formed MUs, and their influence on host muscle. Our model eliminates endogenous MNs, allows for the study of the properties of MUs formed by ES-cell-derived MNs, and demonstrates the high degree to which they recapitulate normal MU properties. In addition, we demonstrate that ES-cell-derived MNs have an 
effect on the host muscle: muscle mass is relatively preserved and there are specific changes to the biochemical make up of the fibers.

In this study, we demonstrate that transplanted ES-cell-derived MNs reinnervate MG muscle fibers of adult host mice. In the animals receiving implants, the muscle retained $42 \%$ of its crosssectional area, $44 \%$ of its tetanic force, and $44 \%$ of the number of MUs. More surprising was the similarity of the range of MU forces (and mean force) between the implanted and the control groups. Given the apparent homogeneity of the ES-cell-derived MNs in culture (Miles et al., 2004), we expected the range and distribution of reinnervated MUs to be more limited because MU force is directly proportional to the size of the innervating $\mathrm{MN}$ in both normal and reinnervated muscles (Gordon and Stein, 1982; Rafuse and Gordon, 1996a). However, the control-like distribution of MU forces produced in the reinnervated muscles, and with each fiber being of normal cross-sectional area, suggests that the ES-cell-derived MNs are actually quite heterogeneous.

It is interesting to note that the ES-cell-derived MNs did not form enlarged MUs to compensate for the reduced number of reinnervating MNs even though many muscle fibers remained denervated. This lack of enlargement contrasts with the expansion of MU size observed in partially denervated muscles (Brown and Ironton, 1978; Rafuse et al., 1992) and muscles reinnervated by $<50 \%$ of their normal complement of MNs (Rafuse and Gordon, 1996a). In both injury models, normal muscle force can be reestablished even when the muscle is innervated by only $20 \%$ of its MNs. It is not entirely clear why ES-cell-derived MNs are incapable of expanding their MU size, but there are several possible explanations. For example, the perikaryon of ES-cellderived MNs may have a reduced capacity to supply synaptic components to an expanded number of NMJs. Indeed, an effective safety factor of neurotransmission at the NMJ is an important factor limiting MU size in partially denervated muscles (Rochel and Robbins, 1988). Alternatively, ES-cell-derived MNs may contain fewer proximal branches. The proximal branches establish MU territory whereas the distal branches innervate the muscle fibers within that MU territory (Kugelberg et al., 1970). Consequently, less proximal branching limits MU size because the proximal branches delineate the area and thus the number of muscle fibers that a single motor axon can innervate (Kugelberg et al., 1970; Rafuse and Gordon, 1996a). Finally, ES-cell-derived MNs may not be as responsive to sprouting cues as the endogenous neurons. That is, there may be a mismatch between the sprouting cues (perhaps CNTF; (Gurney et al., 1992; Sendtner et al., 1992; Smith et al., 1993) released by Schwann cells and the responsiveness of the ES-cell-derived MNs (Son and Thompson, 1995).

There was a change in the composition of the muscle after reinnervation. The mouse MG muscle is predominantly composed of fast contracting MUs (Brasseur et al., 1987). Animals implanted with ES-cell-derived MNs generated MUs with significantly longer rise times and the reinnervated muscles were more resistant to fatigue compared with normal control MG muscles. Immunohistochemical analysis showed that the reinnervated muscle fibers were similar in size to normal MG muscle fibers. Interestingly, the reinnervated MG muscles contained five times more type I muscle fibers compared with normal control and surgical control muscles. Both the reestablishment of muscle fiber size and conversion of fiber types suggests that the ES-cellderived MNs were electrically active (Buller et al., 1960; Luff, 1975; Bagust et al., 1981; Talmadge et al., 1999; Hyatt et al., 2003). In fact, a similar shift toward fatigue-resistant fibers (in their case, type IIa) was found after transplantation of embryonic MNs into rat tibial nerves; this was associated with spontaneous MU activity (Thomas et al., 2003). The relationship of MN firing properties to the muscle fibers they innervate has been well established (Foehring et al., 1987a; Gordon et al., 1997; Rafuse et al., 1997). For example, in cross-reinnervation studies, the contractile and biochemical properties of muscle fibers change to match the firing patterns of the reinnervating $\mathrm{MN}$ [i.e., slow MNs convert type II to type I muscle fibers (Buller et al., 1960; Luff, 1975; Bagust et al., 1981)]. Thus the increase in type I fibers in this study may be attributable to the fact that the ES-cell-derived MNs were tonically active at low firing rates, either because of synaptic connectivity between interneurons and MNs within the graft site (Miles et al., 2004), or because of their intrinsic properties, which are similar to those of slow MNs (Brownstone, 2006; Soundararajan et al., 2006). Alternatively, preliminary evidence suggests that activity may be movement related, perhaps caused by mechanical stimulation by surrounding tissue (supplemental Fig. 1, available at www.jneurosci.org as supplemental material).

Prolonged muscle denervation resulting from $\mathrm{MN}$ damage leads to atrophy and degeneration of the NMJs, which can impart irreversible damage and hinder reinnervation by endogenous axons (Gutmann and Young, 1944). Preservation of the muscle is reliant on maintaining functional NMJs (Fu and Gordon, 1995b, a). Animals implanted with ES-cell-derived MNs demonstrated significant attenuation of muscle atrophy when compared with surgical control muscles after 3 months of denervation. A similar reduction in whole muscle atrophy has been reported after transplantation of embryonic MNs into the rat tibial nerve (Thomas et al., 2000, 2003; Grumbles et al., 2005, 2007).

The functional restoration of host muscle activity by ES-cellderived MNs provides evidence that these cells may be useful for cell replacement therapies. There are several potential therapeutic implications of this work. First, given their capacity to reduce muscle atrophy and maintain NMJs, it is possible that ES-cellderived MNs could be used to preserve muscle after proximal peripheral nerve injury and repair. This may also be a useful adjunct treatment for ALS strategies aimed at regenerating motor axons from the spinal cord to distal sites. Alternatively, transplantation of ES-cell-derived MNs could be used in conjunction with peripheral nerve stimulators when no endogenous motor axons are present, for example after nerve root injuries leading to foot drop (Weber et al., 2005), cervical root injuries leading to loss of hand function (Gan et al., 2007), or with phrenic nerve stimulators (Glenn et al., 1972) in MN diseases.

In summary, we have shown that ES-cell-derived MNs form functionally stable MUs with host muscle without the provision of input from spinal circuitry. Remarkably these results demonstrate the capacity for ES-cell-derived MNs not only to incorporate into the adult host tissue, but also to exert changes in the target tissue. By providing two signals normally active during embryonic development (RA and Shh) and placing the cells in an environment with their target tissue (Schwann cells and muscle), ES cells differentiate into MNs with a range of properties that are extraordinarily similar to endogenous MNs. This suggests that these signals, combined with those present in the graft environment, lead to the activation of a program intended to produce a normal range of $\mathrm{MU}$ forces.

\section{References}

Arber S, Han B, Mendelsohn M, Smith M, Jessell TM, Sockanathan S (1999) Requirement for the homeobox gene $\mathrm{Hb} 9$ in the consolidation of motor neuron identity. Neuron 23:659-674. 
Bagust J, Lewis DM, Westerman RA (1981) Motor units in crossreinnervated fast and slow twitch muscle of the cat. J Physiol 313:223-235.

Björklund A, Dunnett SB, Brundin P, Stoessl AJ, Freed CR, Breeze RE, Levivier M, Peschanski M, Studer L, Barker R (2003) Neural transplantation for the treatment of Parkinson's disease. Lancet Neurol 2:437-445.

Bodine-Fowler S, Garfinkel A, Roy RR, Edgerton VR (1990) Spatial distribution of muscle fibers within the territory of a motor unit. Muscle Nerve 13:1133-1145.

Boillée S, Vande Velde C, Cleveland DW (2006) ALS: a disease of motor neurons and their nonneuronal neighbors. Neuron 52:39-59.

Brasseur JE, Curtis RL, Mellender JW, Rimm AA, Melvin JL, Sulaiman AR (1987) Systematic distribution of muscle fiber types in the medial gastrocnemius of the laboratory mouse: a morphometric analysis. Anat Rec 218:396-401

Brown MC, Ironton R (1978) Sprouting and regression of neuromuscular synapses in partially denervated mammalian muscles. J Physiol 278:325-348.

Brownstone RM (2006) Beginning at the end: repetitive firing properties in the final common pathway. Prog Neurobiol 78:156-172.

Buller AJ, Eccles JC, Eccles RM (1960) Interactions between motoneurones and muscles in respect of the characteristic speeds of their responses. J Physiol 150:417-439.

Burke RE, Levine DN, Tsairis P, Zajac FE 3rd (1973) Physiological types and histochemical profiles in motor units of the cat gastrocnemius. J Physiol 234:723-748.

Deshpande DM, Kim YS, Martinez T, Carmen J, Dike S, Shats I, Rubin LL, Drummond J, Krishnan C, Hoke A, Maragakis N, Shefner J, Rothstein JD, Kerr DA (2006) Recovery from paralysis in adult rats using embryonic stem cells. Ann Neurol 60:32-44.

Erb DE, Mora RJ, Bunge RP (1993) Reinnervation of adult rat gastrocnemius muscle by embryonic motoneurons transplanted into the axotomized tibial nerve. Exp Neurol 124:372-376.

Foehring RC, Sypert GW, Munson JB (1987a) Motor-unit properties following cross-reinnervation of cat lateral gastrocnemius and soleus muscles with medial gastrocnemius nerve. I. Influence of motoneurons on muscle. J Neurophysiol 57:1210-1226.

Foehring RC, Sypert GW, Munson JB (1987b) Motor-unit properties following cross-reinnervation of cat lateral gastrocnemius and soleus muscles with medial gastrocnemius nerve. II. Influence of muscle on motoneurons. J Neurophysiol 57:1227-1245.

Fu SY, Gordon T (1995a) Contributing factors to poor functional recovery after delayed nerve repair: prolonged axotomy. J Neurosci 15:3876-3885.

Fu SY, Gordon T (1995b) Contributing factors to poor functional recovery after delayed nerve repair: prolonged denervation. J Neurosci 15:3886-3895.

Gan LS, Prochazka A, Bornes TD, Denington AA, Chan KM (2007) A new means of transcutaneous coupling for neural prostheses. IEEE Trans Biomed Eng 54:509-517.

Gao J, Coggeshall RE, Tarasenko YI, Wu P (2005) Human neural stem cellderived cholinergic neurons innervate muscle in motoneuron deficient adult rats. Neuroscience 131:257-262.

Gao J, Coggeshall RE, Chung JM, Wang J, Wu P (2007) Functional motoneurons develop from human neural stem cell transplants in adult rats. Neuroreport 18:565-569.

Glenn WW, Holcomb WG, McLaughlin AJ, O’Hare JM, Hogan JF, Yasuda R (1972) Total ventilatory support in a quadriplegic patient with radiofrequency electrophrenic respiration. N Engl J Med 286:513-516.

Gordon T, Stein RB (1982) Time course and extent of recovery in reinnervated motor units of cat triceps surae muscles. J Physiol 323:307-323.

Gordon T, Tyreman N, Rafuse VF, Munson JB (1997) Fast-to-slow conversion following chronic low-frequency activation of medial gastrocnemius muscle in cats. I. Muscle and motor unit properties. J Neurophysiol 77:2585-2604.

Gould TW, Buss RR, Vinsant S, Prevette D, Sun W, Knudson CM, Milligan CE, Oppenheim RW (2006) Complete dissociation of motor neuron death from motor dysfunction by Bax deletion in a mouse model of ALS. J Neurosci 26:8774-8786.

Grumbles RM, Casella GT, Rudinsky MJ, Godfrey S, Wood PM, Thomas CK (2005) The immunophilin ligand FK506, but not the P38 kinase inhibitor SB203580, improves function of adult rat muscle reinnervated from transplants of embryonic neurons. Neuroscience 130:619-630.

Grumbles RM, Casella GT, Rudinsky MJ, Wood PM, Sesodia S, Bent M,
Thomas CK (2007) Long-term delivery of FGF-6 changes the fiber type and fatigability of muscle reinnervated from embryonic neurons transplanted into adult rat peripheral nerve. J Neurosci Res 85:1933-1942.

Gundersen K, Leberer E, Lømo T, Pette D, Staron RS (1988) Fibre types, calcium-sequestering proteins and metabolic enzymes in denervated and chronically stimulated muscles of the rat. J Physiol 398:177-189.

Gurney ME, Yamamoto H, Kwon Y (1992) Induction of motor neuron sprouting in vivo by ciliary neurotrophic factor and basic fibroblast growth factor. J Neurosci 12:3241-3247.

Gutmann E, Young JZ (1944) The re-innervation of muscle after various periods of atrophy. J Anat 78:15-43.

Harper JM, Krishnan C, Darman JS, Deshpande DM, Peck S, Shats I, Backovic S, Rothstein JD, Kerr DA (2004) Axonal growth of embryonic stem cellderived motoneurons in vitro and in motoneuron-injured adult rats. Proc Natl Acad Sci U S A 101:7123-7128.

Huxley AF (1959) Ion movements during nerve activity. Ann N Y Acad Sci 81:221-246.

Hyatt JP, Roy RR, Baldwin KM, Edgerton VR (2003) Nerve activityindependent regulation of skeletal muscle atrophy: role of MyoD and myogenin in satellite cells and myonuclei. Am J Physiol Cell Physiol 285:C1161-C1173.

Jack JJ (1975) Physiology of peripheral nerve fibres in relation to their size. Br J Anaesth 47:173-182.

Jergoviã D, Stål P, Lidman D, Lindvall B, Hildebrand C (2001) Changes in a rat facial muscle after facial nerve injury and repair. Muscle Nerve 24:1202-1212.

Karpati G, Engel WK (1968) “Type grouping” in skeletal muscles after experimental reinnervation. Neurology 18:447-455.

Kugelberg E, Edström L, Abbruzzese M (1970) Mapping of motor units in experimentally reinnervated rat muscle. Interpretation of histochemical and atrophic fibre patterns in neurogenic lesions. J Neurol Neurosurg Psychiatry 33:319-329.

Lewis DM, Parry DJ, Rowlerson A (1982) Isometric contractions of motor units and immunohistochemistry of mouse soleus muscle. J Physiol 325:393-401.

Li XJ, Du ZW, Zarnowska ED, Pankratz M, Hansen LO, Pearce RA, Zhang SC (2005) Specification of motoneurons from human embryonic stem cells. Nat Biotechnol 23:215-221.

Lindvall O, Kokaia Z (2006) Stem cells for the treatment of neurological disorders. Nature 441:1094-1096.

Lubischer JL, Thompson WJ (1999) Neonatal partial denervation results in nodal but not terminal sprouting and a decrease in efficacy of remaining neuromuscular junctions in rat soleus muscle. J Neurosci 19:8931-8944.

Luff AR (1975) Dynamic properties of fast and slow skeletal muscles in the cat and rat following cross-reinnervation. J Physiol 248:83-96.

MacDonald SC, Fleetwood IG, Hochman S, Dodd JG, Cheng GK, Jordan LM, Brownstone RM (2003) Functional motor neurons differentiating from mouse multipotent spinal cord precursor cells in culture and after transplantation into transected sciatic nerve. J Neurosurg 98:1094-1103.

McComas AJ, Fawcett PR, Campbell MJ, Sica RE (1971) Electrophysiological estimation of the number of motor units within a human muscle. J Neurol Neurosurg Psychiatry 34:121-131.

McLeod M, Hong M, Mukhida K, Sadi D, Ulalia R, Mendez I (2006) Erythropoietin and GDNF enhance ventral mesencephalic fiber outgrowth and capillary proliferation following neural transplantation in a rodent model of Parkinson's disease. Eur J Neurosci 24:361-370.

Miles GB, Yohn DC, Wichterle H, Jessell TM, Rafuse VF, Brownstone RM (2004) Functional properties of motoneurons derived from mouse embryonic stem cells. J Neurosci 24:7848-7858.

Miller JB, Crow MT, Stockdale FE (1985) Slow and fast myosin heavy chain content defines three types of myotubes in early muscle cell cultures. J Cell Biol 101:1643-1650.

Mohajeri MH, Figlewicz DA, Bohn MC (1998) Selective loss of alpha motoneurons innervating the medial gastrocnemius muscle in a mouse model of amyotrophic lateral sclerosis. Exp Neurol 150:329-336.

Mrówczyński W, Celichowski J, Krutki P (2006) Interspecies differences in the force-frequency relationship of the medial gastrocnemius motor units. J Physiol Pharmacol 57:491-501.

Naumann K, Pette D (1994) Effects of chronic stimulation with different impulse patterns on the expression of myosin isoforms in rat myotube cultures. Differentiation 55:203-211.

Nemeth PA, Cope TC, Kushner S, Nemeth PM (1993) Spatial arrangement 
and metabolic capacity of fiber types in self-reinnervated cat muscle. Am J Physiol 264:C411-C418.

Pette D, Staudte HW, Vrbová G (1972) Physiological and biochemical changes induced by long-term stimulation of fast muscle. Naturwissenschaften 59:469-470.

Rafuse VF, Gordon T (1996a) Self-reinnervated cat medial gastrocnemius muscles. I. Comparisons of the capacity for regenerating nerves to form enlarged motor units after extensive peripheral nerve injuries. J Neurophysiol 75:268-281.

Rafuse VF, Gordon T (1996b) Self-reinnervated cat medial gastrocnemius muscles. II. Analysis of the mechanisms and significance of fiber type grouping in reinnervated muscles. J Neurophysiol 75:282-297.

Rafuse VF, Gordon T, Orozco R (1992) Proportional enlargement of motor units after partial denervation of cat triceps surae muscles. J Neurophysiol 68:1261-1276.

Rafuse VF, Pattullo MC, Gordon T (1997) Innervation ratio and motor unit force in large muscles: a study of chronically stimulated cat medial gastrocnemius. J Physiol 499:809-823.

Rochel S, Robbins N (1988) Effect of partial denervation and terminal field expansion on neuromuscular transmitter release and nerve terminal structure. J Neurosci 8:332-338.

Schultz E, Jaryszak DL, Gibson MC, Albright DJ (1986) Absence of exogenous satellite cell contribution to regeneration of frozen skeletal muscle. J Muscle Res Cell Motil 7:361-367.

Sendtner M, Stöckli KA, Thoenen H (1992) Synthesis and localization of ciliary neurotrophic factor in the sciatic nerve of the adult rat after lesion and during regeneration. J Cell Biol 118:139-148.

Slack JR, Pockett S (1981) Terminal sprouting of motoneurones is a local response to a local stimulus. Brain Res 217:368-374.

Smith GM, Rabinovsky ED, McManaman JL, Shine HD (1993) Temporal and spatial expression of ciliary neurotrophic factor after peripheral nerve injury. Exp Neurol 121:239-247.
Son YJ, Thompson WJ (1995) Nerve sprouting in muscle is induced and guided by processes extended by Schwann cells. Neuron 14:133-141.

Soundararajan P, Miles GB, Rubin LL, Brownstone RM, Rafuse VF (2006) Motoneurons derived from embryonic stem cells express transcription factors and develop phenotypes characteristic of medial motor column neurons. J Neurosci 26:3256-3268.

Stein RB, Yang JF (1990) Methods for estimating the number of motor units in human muscles. Ann Neurol 28:487-495.

Stein RB, Gordon T, Shriver J (1982) Temperature dependence of mammalian muscle contractions and ATPase activities. Biophys J 40:97-107.

Talmadge RJ, Roy RR, Edgerton VR (1999) Persistence of hybrid fibers in rat soleus after spinal cord transection. Anat Rec 255:188-201.

Thaler J, Harrison K, Sharma K, Lettieri K, Kehrl J, Pfaff SL (1999) Active suppression of interneuron programs within developing motor neurons revealed by analysis of homeodomain factor HB9. Neuron 23:675-687.

Thomas CK, Erb DE, Grumbles RM, Bunge RP (2000) Embryonic cord transplants in peripheral nerve restore skeletal muscle function. J Neurophysiol 84:591-595.

Thomas CK, Sesodia S, Erb DE, Grumbles RM (2003) Properties of medial gastrocnemius motor units and muscle fibers reinnervated by embryonic ventral spinal cord cells. Exp Neurol 180:25-31.

Weber DJ, Stein RB, Chan KM, Loeb G, Richmond F, Rolf R, James K, Chong SL (2005) BIONic WalkAide for correcting foot drop. IEEE Trans Neural Syst Rehabil Eng 13:242-246.

Wichterle H, Lieberam I, Porter JA, Jessell TM (2002) Directed differentiation of embryonic stem cells into motor neurons. Cell 110:385-397.

Zardini DM, Parry DJ (1998) Physiological characteristics of identified motor units in the mouse extensor digitorum longus muscle: an in vitro approach. Can J Physiol Pharmacol 76:68-71.

Zhan WZ, Swallow JG, Garland T Jr, Proctor DN, Carter PA, Sieck GC (1999) Effects of genetic selection and voluntary activity on the medial gastrocnemius muscle in house mice. J Appl Physiol 87:2326-2333. 